\title{
The Morphology and Clinical Considerations of Mucosal Folds of Cystic Duct
}

\author{
Jaba Rajguru', Mitesh R. Dave', Pratik N. Mistry \\ ${ }^{1}$ Associate Professor, Department of Anatomy, Parul Institute of Medical Sciences \& Research, Parul University, Vadodara, Gujarat, India, ${ }^{2}$ Assistant \\ Professor, Department of Anatomy, Parul Institute of Medical Sciences \& Research, Parul University, Vadodara, Gujarat, India.
}

\section{Abstract}

Introduction: The cystic duct connects the gallbladder to the extra hepatic bile duct. In its endoluminal surface are the mucosal folds which are characteristic of the duct. Aim:-The aim was to study the length and mid-length diameter of the cystic duct and the mucosal folds of its endoluminal surface with respect to their number, location, and orientation. Subjects and Methods: This study was carried out in the Anatomy Department of Parul Institute of Medical Sciences and Research, Vadodara, on 40 specimens of 10\% formalin fixed human cystic ducts, from 2015 to 2018, after obtaining permission from the Institutional Ethics Committee. The cystic duct was isolated and its lumen was exposed by an incision parallel to its length to study the folds. Results: The length of the cystic duct was between 0.4 to 4.2 $\mathrm{cm}$, and the diameter was between $0.2-0.6 \mathrm{~cm}$. The mucosal folds were present in 38(95\%) specimens and were absent in two (5\%). The maximum number of mucosal folds present in a specimen was eleven. In the $25(62.5 \%)$ specimens they spanned the entire length and in $13(32.5 \%)$ they were present only in the proximal part. Their disposition was either oblique, transverse interdigitating, combination type or saccular. Conclusion: It gives insight into the internal morphology of the cystic duct. Various types of mucosal folds have been described, the knowledge of which will be important to the laparoscopic surgeons during various interventional approaches undertaken in this region.

Keywords: Oblique, Spiral, Transverse, Interdigitating, Endoluminal.

Corresponding Author: Dr. Mitesh. R. Dave, C-401, Sharnam flats, B/h Shivdarshan Complex, Near Gadaa Circle, Harni-390022, Vadodara, Gujarat, India.

Received: March 2019

Accepted: March 2019

\section{Introduction}

The cystic duct is a narrow conduit that allows the flow of bile to and away from the gall bladder. Inside the endoluminal surface, wavy mucosal folds are present which are commonly known as the "Spiral valves of Heister". They are said to be characteristic of the duct and are described as corkscrew tortuosities seen on endoscopic retrograde cholangiography. ${ }^{[1]}$ They are mostly concentrated in the proximal part of the duct. They are enigmatic and perplexing at the same time, as though they were described over 300 years ago by the German Anatomist Lorenz Heister, ${ }^{[2-5]}$ nothing definite is known about the structure and function of these mucosal folds: a lot of speculation still persists. There is an extreme paucity of literature about the structure of these folds with by far and occasional references. They are thought to control the flow of bile to and away from the gallbladder by providing an architectural mechanism which aids in keeping the cystic duct patent, ${ }^{[2]}$ thereby regulating the filling and emptying of the viscus. They are said to have a role in the genesis of cholelithiasis. ${ }^{[6]}$

The cystic duct attaches the gallbladder to the common hepatic duct to form the common bile duct. Its length is variable, but it is usually $2-4 \mathrm{~cm}$ long and has a diameter of $0.1-0.5 \mathrm{~cm} .{ }^{[7]}$ It often has a tortuous/serpentine course. The shape of the cystic duct has been described to be either Sshaped, curved or straight. ${ }^{[3]}$ The shape may vary with the filling and emptying of the gall bladder and it is prone to develop kinks all along its course. In the majority of the cases, the cystic duct joins the common hepatic duct at the middle third of the total length of the common hepatic and common bile ducts to form the common bile duct, but the junction might occur anywhere from the porta hepatis to the ampulla of Vater, and in certain cases it drains into the hepatic ducts or open independently into the duodenum. The course of the cystic duct is described to be angular, parallel, or spiral. Its junction with respect to the common hepatic duct is either on its anterior, posterior, lateral or medial aspect. The cystic duct can be divided into two parts (i) the pars spirals or the proximal duct or the pars convoluta where the mucosal folds are well developed, and (ii) the pars glabra i.e. the distal part where the folds flatten out and could even be absent. ${ }^{[4]}$ The mucosa of the endoluminal surface is coarser and velvety than that of the gall bladder. ${ }^{[1]}$ Inside the endoluminal surface of the cystic duct there are about 2-10 crescentic folds which project into the lumen. They are conventionally thought to run in a clockwise spiral 
manner. ${ }^{[2]}$ Under the microscope, the proximal portion shows the reticular network of intricate folds, whereas, in the distal part, it shows folds which are longitudinal and parallel to each other. ${ }^{[3]}$

\section{$\underline{\operatorname{Aim}}$}

This study was conducted with the aim to examine the length of the cystic duct, its mid-length diameter, and study the mucosal folds present in its endoluminal surface with regards to the number, location, and orientation.

\section{Subjects and Methods}

This prospective, observational study was carried out in the Anatomy Department of Parul Institute of Medical Sciences and Research on 40 specimens of the intact cystic ducts, during a three year period i.e. from 2015 to 2018. The specimens were procured from $10 \%$ formalin fixed adult human cadavers during the routine undergraduate dissection. Necessary permission from the Institutional Ethics Committee was obtained before commencing the study. Cadavers with a history of abdominal surgery and crush injury to abdomen were excluded from the study. The anatomy of the bile ducts was studied carefully in situ and then the extra hepatic biliary ducts along with the liver, gallbladder, duodenum, and the pancreas were removed enbloc from cadavers (age 65-88 years) and cleaned with water. The cystic duct was isolated carefully and the length and the external mid-length diameter were noted with the help of a calibrated scale \& measuring tape.The lumen was then exposed by an incision parallel to the length of the duct, along with its course. The number, location and orientation of the mucosal folds were carefully studied and noted. Magnifying lenses were used as and when required. Necessary photographs were taken, sketches were made and the results were tabulated, interpreted and analysed accordingly. Descriptive statistics was used to present the findings of the study.

\section{Results}

1. The length of the cystic duct was found to be ranging from 0.4 to $4.2 \mathrm{~cm}$. The distribution of lengths is presented in [Graph 1].

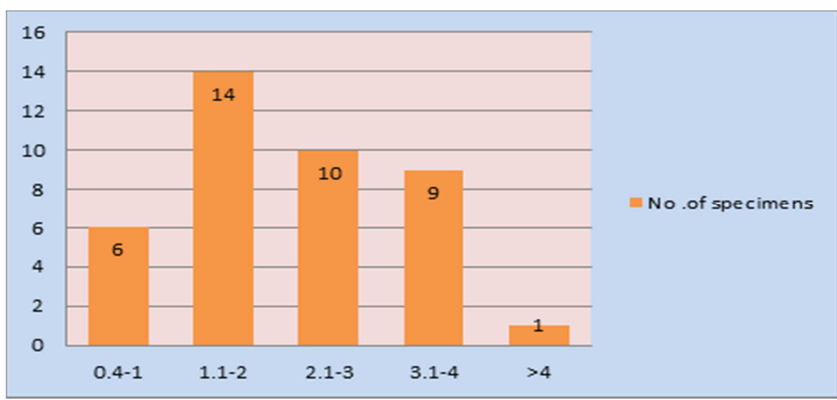

Graph 1: Distribution of lengths (cm) of the cystic duct

2. The external mid-length diameter was found to be ranging from 0.2 to $0.6 \mathrm{~cm}$ with $17(42.5 \%)$ specimens having their diameter at $0.4 \mathrm{~cm}$. The distribution of midlength diameter is given in [Table 1].

\begin{tabular}{|l|l|l|l|l|l|}
\hline Table 1: Distribution of Mid-length Diameter of Cystic Duct. \\
\hline $\begin{array}{l}\text { Mid-length } \\
\text { diameter }(\mathbf{c m})\end{array}$ & $0.2-0.3$ & 0.4 & 0.5 & 0.6 \\
\hline $\begin{array}{l}\text { No of } \\
\text { specimens }\end{array}$ & 8 & 17 & 8 & 7 \\
\hline
\end{tabular}

3. Distribution of mucosal folds. The mucosal folds were present in $38(95 \%)$ specimens [Figure 1] and were absent in two $(5 \%)$ cystic ducts [Figure 2]. The number of mucosal folds ranged from $0-11$ in number. The majority of the specimens i.e.10 (25\%) had five mucosal folds each. The distribution of the mucosal folds is shown in [Graph 2].

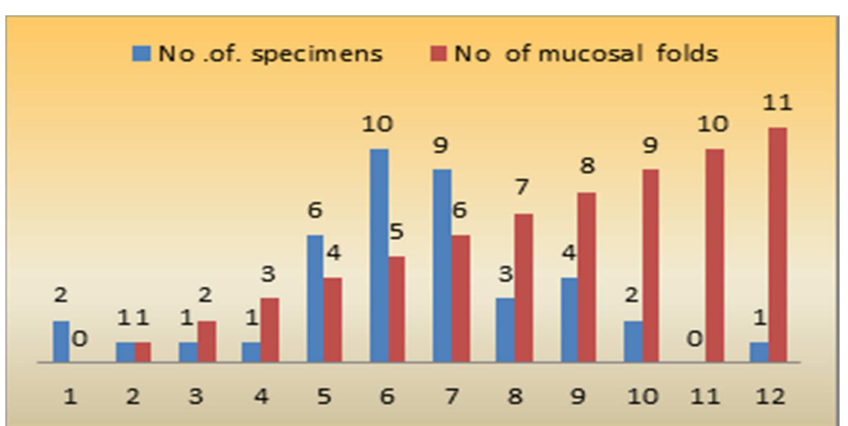

Graph 2: Distribution of mucosal folds with respect to the number of specimens

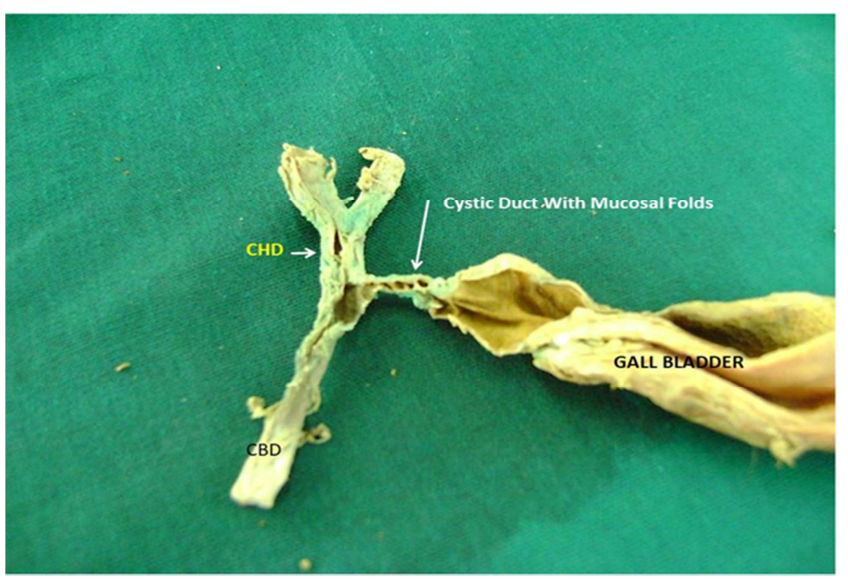

Figure 1: Oblique disposition of mucosal folds filling the entire cystic duct (CBD- Common bile duct, CHD -Common hepatic duct)

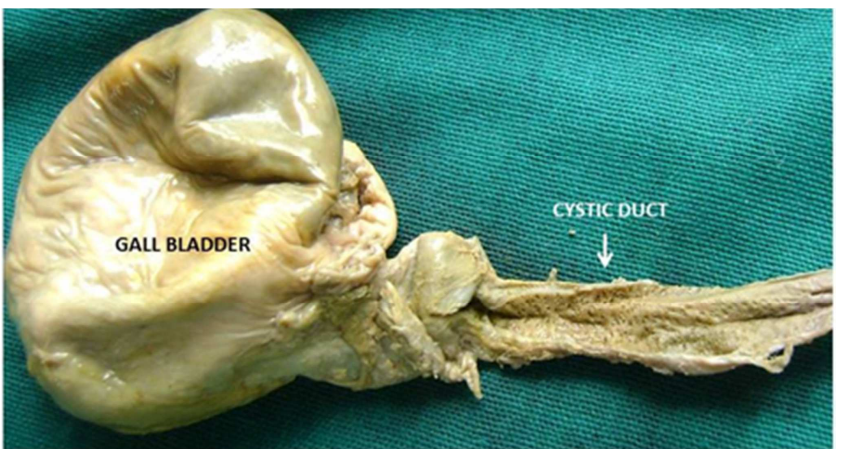

Figure 2: Endoluminal surface of cystic duct without mucosal folds 


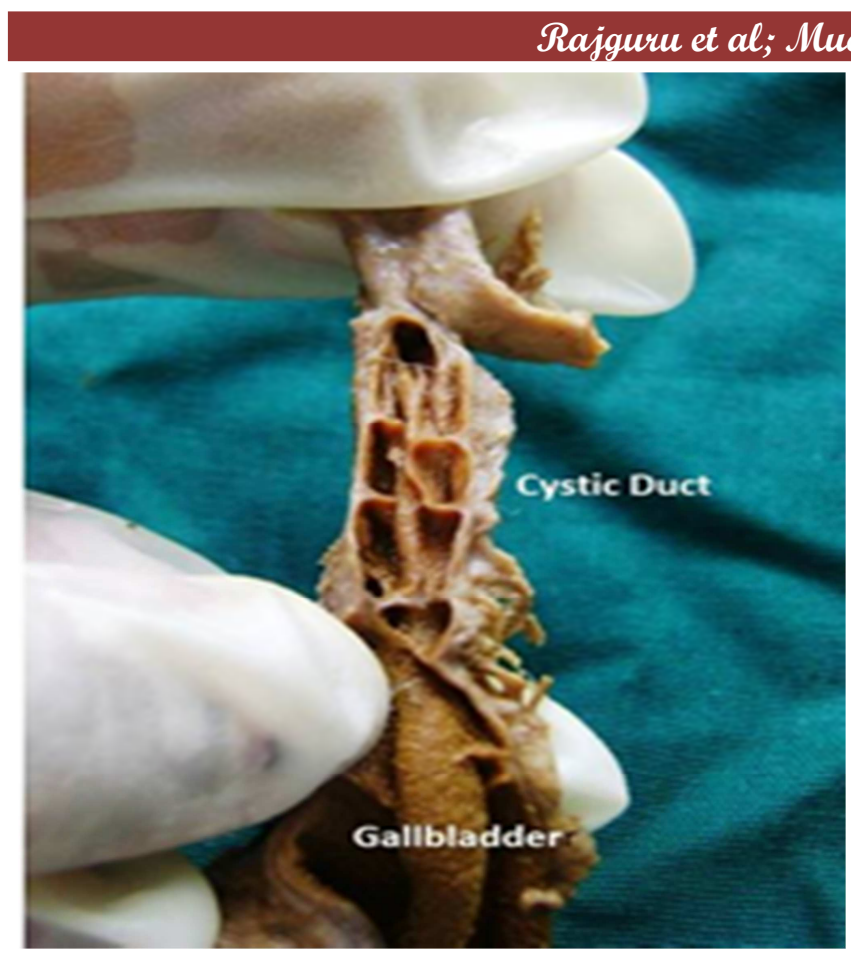

Figure 3: Saccular arrangement of mucosal folds

4. Location of the mucosal folds. In $25(62.5 \%)$ specimens they were present thought out the entire length of the cystic duct [Figure 1]. In $13(32.5 \%)$ they were present only in the gallbladder end, i.e. the proximal part [Figure $3]$ whereas there were none in the distal part of the duct.

5. The orientation of the mucosal folds as observed in the longitudinal cut section were either oblique/spiral or transverse to the long axis of the duct or interdigitating or saccular or random (combination of above). They were either even or uneven in their placement. Even or irregular placements were seen in $10(25 \%)$ and uneven or irregular in $28(70 \%)$ specimens. The description of the mucosal folds is given in the following paragraphs.

i. The Oblique orientation was observed in $20(50 \%)$ specimens [Figure 1] wherein 12(30\%) specimens they filled the entire duct and in $8(20 \%)$ specimens they were present in the proximal part of the duct. Even spacing was observed in $6(15 \%)$ specimens out of the twelve where it filled the entire duct. In the remaining 14(35\%) the distance between the folds was found to be uneven.

ii. The transverse orientation of mucosal folds was observed in $5(12.5 \%)$ specimens. In all these they were present in the proximal part of the duct. In $2(5 \%)$ the folds were evenly placed and in $3(7.5 \%)$ the distance between the folds was varying and hence uneven in placements.

iii. The interdigitating pattern was seen in $3(7.5 \%)$ specimens. The folds consisted of half turns where mucosal projections of one wall were seen to alternate with that of the opposite wall of the $\mathrm{CD}$. They were seen to be present throughout the length of the duct. They were evenly placed in $1(2.5 \%)$ specimen and in $2(5 \%)$ the distance between the folds was uneven.

iv. Combination type. Randomly oriented mucosal folds with a combination of the transverse, oblique were present in $9(22.5 \%)$ specimens out of which in $1(2.5 \%)$ an inverted $\mathrm{C}$-shaped fold along with three rudimentary straight ridges were present. The folds were present throughout the whole length of the duct and had uneven spacing between them.

v. Saccular configuration [Figure 3]. In 1(2.5\%) specimen the mucosal folds were placed such that the transverse folds were intersected in the middle by a longitudinal septum diving the cystic duct into small sacs giving rise to a saccular appearance. The transverse folds were regular in their arrangement.

\section{Discussion}

The maximum number of biliary injuries which occur during laparoscopic cholecystectomy is due to misidentification of the cystic duct. ${ }^{[3]}$ The cystic duct has a complicated anatomy which is very important from the surgical point of view. Its anatomical features are often closely related to diseases of gallbladder such as calculus disease, primary sclerosing cholangitis, cholangiocarcinoma, and other inflammatory and neoplastic conditions. ${ }^{[7]}$ It has been often hypothesized that a small lumen with a large number of mucosal folds acts as a predisposing factor in the development of cholelithiasis. ${ }^{[5]}$ Though there are many studies detailing the external morphology of the cystic duct, there has hardly been any study relating the mucosal folds to the diseases of the extrabiliary ducts apart from gallstones. There are only two published gross morphological studies of the mucosal folds of cystic duct in the recent literature, to the best of our knowledge.

During the fourth week of intrauterine life, an endodermal bud arises in the ventral wall of the primitive foregut of the embryo. This bud which is known as the hepatic diverticulum soon divides into two parts: the proximal bud is solid and is called the pars hepatica and the distal one is hollow and is known as pars cystica. The pars hepatica gives rise to the liver and intrahepatic biliary ducts, whereas the pars cystica serves as the primordium of the gall bladder, its stalk gives rise to the cystic duct. The hollow pars cystica eventually gets obliterated due to the rapidly proliferating epithelial cells. Later on, it gets fully canalized and is in full communication with the biliary tree. Recent literature suggests that the biliary tree is patent from the very beginning and does not go through the process of occlusion and recanalization. ${ }^{[8]}$ Wnt, Notch, sonic hedgehog, transforming growth factor $\beta 3$ cell signaling pathways have been reported to regulate the development of the liver and biliary apparatus. ${ }^{[8]}$ Recently Lgr4 gene has been shown to regulate the development of the gall bladder and cystic duct. $^{[9]}$ The variations seen in its anatomy are the consequences of aberrations in the developmental process taking place during this crucial period of organogenesis in prenatal life. ${ }^{[8]}$

Variability in the length of the cystic duct ranges from being absent, ${ }^{[10,11]}$ to short, ${ }^{[12,13]}$ and long, ${ }^{[12-14]}$ cystic ducts. Its length is directly proportional to the length of the common hepatic duct and inversely proportional to the common bile duct. The incidence of short cystic duct has been reported to be $1.3 \%-2.6 \%$ in the recent studies. ${ }^{[12]}$ In our previous study, ${ }^{[15]}$ short \& long cystic ducts were found in $3 \%$ and $14 \%$ of the cases respectively, in comparison to $2.5 \%$ short 
and another $2.5 \%$ long ones in the present study. The absent or short cystic duct is a rare congenital anomaly which is important from the surgical point of view. Short $(<5 \mathrm{~cm})$ and long $(4 \mathrm{~cm})$ cystic ducts are prone to biliary injury during surgery. ${ }^{[12]}$ The long ones are often associated with the low junction with common hepatic duct and have the propensity to develop common bile duct stones. ${ }^{[4,12]}$ Long cystic ducts are known to have a higher rate of recurrence of the same. ${ }^{[12]}$ The mid-length diameter of the cystic duct was found to be ranging from 0.2 to $0.6 \mathrm{~cm}$ in the present study whereasin our previous study it was found to be ranging from 0.2 to $0.8 \mathrm{~cm} .{ }^{[15]}$ In $65 \%$ the diameter was within the normal range in this study which is in similar to the findings of a recent South American study. ${ }^{[16]}$ The cystic duct is the narrowest part of the biliary tree. The term cystic hypertrophy is a condition characterized by the increase in its diameter of more than $0.5 \mathrm{~cm} .{ }^{[17]}$ The increase in diameter is associated with the increase in the degree of severity of cholelithiasis and consequently, the patients without any evidence of gallbladder stones have the narrowest and those with common bile duct stones have the maximum diameters. The increase in the diameter above the normal values in $37.5 \%$ of specimens in this study, could be because of decrease in the tone of the duct due to old age, or complete lack of it following death. Stones of the biliary tract were not detected during the study. On the flip side, an increase in diameter of the cystic duct aids the laparoscopic surgeons and radiologists in instrumentation during endoscopic retrograde cholangiography and other therapeutic procedures.

The internal disposition of the cystic duct is a consequence of its development in a very congested space in the abdomen, i.e. between the liver and diaphragm. They were believed to be an adaptation for the erect posture of man, but this particular theory has been debunked now as they are also seen to be present in some of the lower animals. Varied terminologies are used to describe them such as spiral valves, leaflets, baffles, baffle plates, cystic folds, etc. A number of functions such as the storage of bile absorption of fluids and lipids, sphincteric action, regulation of filling and emptying of the gallbladder, maintaining the patency of the cystic duct under conditions of increased abdominal pressure has been attributed to them. Dasgupta and Stinger are of the opinion that the folds may be helpful in maintaining the patency and caliber of the duct rather than functioning as a valvular mechanism. Their exact function is yet to be ascertained accurately. A recent South American study has described them to be an inessential element of bile reflux. ${ }^{[16]}$ Laparoscopic surgeons describe these mucosal folds as obstacles which make it difficult to cannulate the cystic duct. $^{[1,16-19]}$ Some authors believe that mucosal folds are a boon in disguise as they help to restrain sludge and stones while allowing the regular flow of bile during cholecystectomy.

Researchers have tried to study the endoluminal surface of the human cystic duct by various methods such as cadaveric studies, casting, 3D scanning, high definition video endoscopy etc. As the bulk of the studies conducted are at autopsy, there is a high possibility of alteration of the usual anatomy by the surfactant properties of bile. Nowadays computer reconstruction and translation are being done to study the fluid mechanics of the cystic duct. These studies, however, do not throw adequate light on the complex internal anatomy of the cystic duct, the geometry of which has been described as being intensely intricate when seen in computer translation.

Though the mucosal folds are said to be typical of the cystic duct, yet we found that in $5 \%$ of the specimens were devoid of any folds. The absence of mucosal folds has been reported to be ranging from $2 \%$ to $22.5 \%$ in world literature. ${ }^{[2,16,18,19]}$ They are reported to be absent in healthy ducts as well. In this study, the maximum number of mucosal folds present in a single duct is more than that found in the recent literature ${ }^{[16,19]}$ but less than that found in the pioneering study by Menzer, where he found 22 folds. In $62.5 \%$ they spanned throughout its length in this study, which is more than that of a recent study. ${ }^{[16]}$ In the specimens where the folds were not present over the entire length of the duct, they were concentrated in the gallbladder and in the present study whereas, in the aforesaid study, ${ }^{[17]}$ they were concentrated either in the proximal or at the distal end. The findings of different researchers as compared to the present study are shown in [Table 2].

Table 2: Comparison between the findings of various authors with the present study in recent literature.

\begin{tabular}{|l|l|l|l|}
\hline Authors & $\begin{array}{l}\text { No of cystic } \\
\text { duct with } \\
\text { mucosal folds }\end{array}$ & $\begin{array}{l}\text { No of cystic } \\
\text { duct without } \\
\text { mucosal fold }\end{array}$ & $\begin{array}{l}\text { Maximum no of } \\
\text { mucosal folds } \\
\text { found in a cystic } \\
\text { duct }\end{array}$ \\
\hline $\begin{array}{l}\text { Ignjatovic et } \\
\text { al, 2012, } \\
\mathrm{n}=70,{ }^{1[8]}\end{array}$ & $67(95.71 \%)$ & $3(4.2 \%)$ & 5 \\
\hline $\begin{array}{l}\text { Pina LN et } \\
\text { al, 2015, } \\
\mathrm{n}=46,{ }^{[16]}\end{array}$ & $32(69.56 \%)$ & $14(30.43 \%)$ & 8 \\
\hline $\begin{array}{l}\text { Present } \\
\text { study } \\
\mathrm{n}=40 \text { (2015- } \\
18)\end{array}$ & $38(95 \%)$ & $2(5 \%)$ & 11 \\
\hline
\end{tabular}

Consecutive oblique / evenly spaced crescentic folds give an impression of the spiraling pattern which was present in $50 \%$ of the specimens in the present study. Oblique and transverse folds have been also observed by Pina et al. The perception of the mucosal folds being present in a spiral manner are based on the initial diagrams of Heister, pictures were taken during cholangiography and the depictions on corrosion cast. Though the presence of a constant clockwise pattern of three and a half spirals has been mentioned by some authors, lack of continuity between adjoining folds and the absence of a regular pattern was observed in the present study and in another study in recent literature.

Ducts with the transverse interdigitating type of folds as seen in the present study have been occasionally cited in the literature. The combination type (random arrangement) and the saccular pattern as found in this series has not been described in the literature as yet and this may be the first instance of reporting it. The uneven spacing of the folds could be a consequence of its degeneration or improper development. Continuous oblique folds interrupted by the longitudinal incision could have given rise to the appearance of the interdigitating pattern as noticed in $7.5 \%$ in this study. Combination type of configuration could be a variant of the normal anatomy or a result of an occult underlying disease 
process or could be due to the degenerative changes taking place after death. Saenz attributed the failure in transcystic exploration in $6 \%$ of his cases to the "not so favorable anatomy" present inside the lumen because of the folds. ${ }^{[19]}$ The mucosal folds of the cystic duct and associated technicalities involved has to be taken into consideration while determining the best site to perform cysticotomy. Percutaneous transcholecystic biliary procedures also being increasingly performed nowadays. Therefore the knowledge of the orientation of the mucosal folds is crucial and will serve as a valuable guide for surgeons while exploring the extrahepatic biliary passages especially via the transcystic approach, in the managementof cholelithiasis and diagnosis of unsuspected choledocholithiasis. ${ }^{[19]}$ It will also provide valuable information indetermining the site of cystic duct division along with other factors such as duct permeability, length and breadth of the cystic duct during laparoscopic cholecystectomy.

\section{Limitations}

1. The study was a cadaveric study and hence the surfactant properties of bile and also some amount of decay could have altered the anatomy.

2. The use of resin casting also could have given us a better understanding of the morphological features of the endoluminal surface of the cystic duct.

\section{Conclusion}

This study gives insight into the internal morphology of the cystic ductwhich is rarely mentioned in the literature. The external morphology with respect to the length and diameter were found within usual range but the various types of mucosal folds as described in this study has been rarely reported in literature. The term spiral valves may be a misnomer as a spiraling pattern was not well appreciated in the study. A minimally invasive surgeon has to bear in mind the relevant anatomy, especially during the transcystic approach so that the cystic duct does not get injured and unnecessary complications can be avoided at surgery paving way to the successful outcome and uneventful convalescence.

\section{References}

1. Zimmer V. Spiral valves of Heister as visualized by direct cystic ductoscopy. GastrointestEndosc. 2018 Jun; 87(6):1587-1589. https://www.giejournal.org/article/S0016-5107(17)32480-X/full text

2. Mentzer SH. The valves of Heister.Archives of Surgery. 1926 Oct 1;13(4):511-22.

https://jamanetwork.com/journals/jamasurgery/articleabstract $/ 537732$

3. Dasgupta D, Stringer MD. Cystic duct and Heister's "valves". Clinical Anatomy: The Official Journal of the American Association of Clinical Anatomists and the British Association of Clinical Anatomists. 2005 Mar; 18(2):81-7. https://onlinelibrary.wiley.com/doi/abs/10.1002/ca.20118

4. Bird NC, Ooi RC, Luo XY, Chin SB, Johnson AG. Investigation of the functional three-dimensional anatomy of the human cystic duct: A single helix? Clinical Anatomy: The Official Journal of the American Association of Clinical Anatomists and the British Association of Clinical Anatomists. 2006 Sep; 19(6):528-34 https://onlinelibrary.wiley.com/doi/abs/10.1002/ca.20219

5. Ooi RC, Luo XY, Chin SB, Johnson AG, Bird NC. The flow of bile in the human cystic duct.Journal of biomechanics. 2004 Dec 1; 37(12):1913-22.

https://www.sciencedirect.com/science/article/pii/S0021929004001 186?via\%3Dihub

6. Deenitchin GP, Yoshida J, Chijiiwa K, Tanaka M. Complex cystic duct is associated with cholelithiasis. HPB Surgery. 1998; 11(1):33-7.

https://www.ncbi.nlm.nih.gov/pmc/articles/PMC2423916/

7. Turner MA, Fulcher AS. The cystic duct: normal anatomy and [1] disease processes. Radiographics. 2001; 21(1):3-22. https://pubs.rsna.org/doi/full/10.1148/radiographics.21.1.g01ja093

8. Keplinger KM, Bloomston M. Anatomy and embryology of the biliary tract. SurgClin North Am. 2014;94(2):203-17. https://www.sciencedirect.com/science/article/pii/S0039610914000 024?via\%3Dihub

9. Yamashita R, Takegawa Y, Sakumoto M, Nakahara M, Kawazu H, Hoshii T, Araki K, Yokouchi Y, Yamamura KI. Defective development of the gall bladder and cystic duct in Lgr4 hypomorphic mice.Developmental Dynamics. 2009 Apr;238(4):993-1000.

https://onlinelibrary.wiley.com/doi/full/10.1002/dvdy.21900.

10. Patil S, Jain S, Kaza RCM, Chamberlain RS. Congenital Absence of the Cystic Duct.A Rare but Significant Anomaly.Surgical Science. 2013;4(4):241-46 https://pdfs.semanticscholar.org/9db8/9ae5da12aba8055ca6c9a899 de9dfc18707e.pdf

11. Khan AS, Paracha SA, Shah Z, Tahir M, Wahab K. Anatomical variations of cystic duct encountered during open cholecystectomy. Khyber Medical University Journal. 2012; 4(1):19-22. https://www.kmuj.kmu.edu.pk/article/view/8614

12. Sarawagi R, Sundar S, Gupta SK, Raghuwanshi S. Anatomical variations of cystic ducts in magnetic resonance cholangiopancreatography and clinical implications. Radiology research and practice. 2016;2016. https://www.hindawi.com/journals/rrp/2016/3021484/

13. Talpur KAH, Syed BM, Sangrasi AK, Laghari AA, Malik AM, Qureshi JN. Cystic duct anomalies and their surgical implications patients undergoing laparoscopic cholecystectomy. J LiaquatUni Med Health Sci. 2016;15(2):63-66. http://www.scopemed.org/?mno=236587

14. Yu JJ, Morell M, Lee JG, Imagawa DK. A case report on a rare anatomic variant of cystic duct insertion.Journal of surgical case reports. $2017 \quad$ Jul https://academic.oup.com/jscr/article/2017/7/rjx131/3960314

15. Rajguru J, Dave M. Cystic Duct Aberrations and its Clinical Significance. International Journal of Anatomy, Radiology, and Surgery. 2018 Apr; 7(2): 23-28. http://www.ijars.jcystic ductr.net/articles/PDF/2386/35596_CE[VSU]_F(AnG)_PF1(VSU_ AnG)_PFA(AnG)_PB(VSU_AnG)_PN(AnG).pdf

16. Pina LN, Samoilovich F, Urrutia S, Rodríguez A, Alle L, Ferreres AR. Surgical considerations of the cystic duct and Heister valves. The Surgery Journal. 2015 Dec;1(01):e23-7. https://www.ncbi.nlm.nih.gov/pmc/articles/PMC5530626/

17. Sureka B, Bansal K, Patidar Y, Arora A. Magnetic resonance cholangiographic evaluation of intrahepatic and extrahepatic bile duct variations. The Indian journal of radiology \& imaging. 2016 Jan;26(1):22. https://www.ncbi.nlm.nih.gov/pmc/articles/PMC4813070/

18. Ignjatovic D, Duric B, Živanović V. Where to incise and/or divide the cystic duct.Actachirurgicalugoslavica. 2002; 49(1):99-101. https://www.researchgate.net/profile/Vladimir_Zivanovic/publicati on/215689376_Where_to_incise_andor_divide_the_cystic_duct/lin ks/583bed6f08aed5c6148cabdb/Where-to-incise-and-or-divide-thecystic-duct.pdf

19. Sáenz A, Amador MA, Martínez I, Astudillo E, Fernández-Cruz L. Choledocholithiasis no sospechada: abordajelaparoscópico Durante la colecistectomía. Cirugía Española. 2002 Jan 1;71(2):68-74. http://www.elsevier.es/es-revista-cirugia-espanola-36-articulocoledocolitiasis-no-sospechada-abordaje-laparoscopicoS0009739X02719337 
Copyright: ( ) the author(s), publisher. Academia Anatomica International is an Official Publication of "Society for Health Care \& Research Development". It is an open-access article distributed under the terms of the Creative Commons Attribution Non-Commercial License, which permits unrestricted non-commercial use, distribution, and reproduction in any medium, provided the original work is properly cited.

How to cite this article: Rajguru J, Dave MR, Mistry PN. The Morphology and clinical Considerations of Mucosal Folds of Cystic Duct. Acad. Anat. Int. 2019;5(1):62-67.

DOI: dx.doi.org/10.21276/aanat.2019.5.1.14

Source of Support: Nil, Conflict of Interest: None declared. 